REVIEW

\title{
Association between thyroid function tests at baseline and the outcome of patients with sepsis or septic shock: a systematic review
}

\author{
Anna G Angelousi ${ }^{1}$, Drosos E Karageorgopoulos ${ }^{1}$, Anastasios M Kapaskelis ${ }^{1,2}$ and Matthew E Falagas ${ }^{1,2,3}$ \\ ${ }^{1}$ Alfa Institute of Biomedical Sciences (AIBS), 9 Neapoleos Street, 15123 Marousi, Athens, Greece, ${ }^{2}$ Department of Medicine, Henry Dunant Hospital, \\ 11526 Athens, Greece and ${ }^{3}$ Department of Medicine, Tufts University School of Medicine, Boston 02153, Massachusetts, USA \\ (Correspondence should be addressed to M E Falagas at Alfa Institute of Biomedical Sciences (AIBS); Email: m.falagas@aibs.gr)
}

\begin{abstract}
Introduction: The severity of critical illness is associated with various patterns of thyroid hormone abnormalities. We sought to evaluate whether the outcome of patients with, specifically, sepsis or septic shock is associated with the thyroid function tests evaluated at diagnosis or admission in the intensive care unit (ICU).

Methods: We performed a systematic review of relevant studies by searching PubMed.

Results: We included nine studies that all had a prospective cohort design. Seven involved children or neonates, and two involved adults. Mortality was the outcome evaluated in eight studies, while the length of ICU stay was evaluated in the remaining study. In univariate analysis, six of the nine included studies showed that either, free or total, triiodothyronine or thyroxine was lower in the group of patients with sepsis or septic shock who had unfavorable outcome than in those who had favorable outcome. Two other studies showed higher TSH values in the group of patients with unfavorable outcome. No significant relevant findings were observed in the remaining study. Regarding the correlation of sepsis prognostic scoring systems with thyroid function tests, the three studies that provided specific relevant data showed variable findings.

Discussion: Most of the relevant studies identified favor the concept that decreased thyroid function at baseline might be associated with a worse outcome of patients with sepsis or septic shock. Although these findings are not consistent, the role of thyroid function in affecting or merely predicting the outcome of sepsis or septic shock merits further investigation.
\end{abstract}

European Journal of Endocrinology 164 147-155

\section{Introduction}

Thyroid hormones play an important role in the adaptation of metabolic function to stress and critical illness (1). In hospitalized patients, thyroid hormone alterations are very common, particularly in those of increased age or in those with critical illness $(2,3)$. Low triiodothyronine $\left(\mathrm{T}_{3}\right)$ is commonly observed in the latter group of patients, which can be attributed to increased deiodination of thyroxine $\left(\mathrm{T}_{4}\right)$ to reverse $\mathrm{T}_{3}\left(\mathrm{rT}_{3}\right)$, rather than $\mathrm{T}_{3}$, and increased catabolism of $\mathrm{T}_{3}$ to 3,3-diiodothyronine $\left(\mathrm{T}_{2}\right)$ (4-6). With increasing severity of illness, low total and free $\mathrm{T}_{4}$, and sometimes low TSH, can be observed (6). Decrease in plasma $\mathrm{T}_{4}$-binding globulin (TBG) or transthyretin as well as accumulation of substances that lower the plasma thyroid hormone-binding capacity appear also to be important for the above-mentioned alterations in thyroid hormone levels during critical illness (4).

For the vast majority of patients, thyroid function abnormalities observed during critical illness are transient and do not represent an underlying thyroid disease (7). Still, certain data suggest that the magnitude of thyroid hormone alterations in patients admitted to the intensive care unit (ICU) due to various causes is associated adversely with the patient outcome (8-11). In this review, we sought to evaluate systematically the association between baseline thyroid function and the outcome of patients with, specifically, sepsis or septic shock.

\section{Methods}

\section{Data sources}

To identify studies eligible for inclusion in this review, we searched PubMed, on February 1, 2009, applying the following combined search term: (thyroid disease OR thyroid OR hypothyroidism OR hyperthyroidism OR $\mathrm{TSH} \mathrm{OR} \mathrm{T}_{4} \mathrm{OR} \mathrm{T}_{3}$ OR thyroid hormones) AND (infection OR sepsis OR bacteremia OR pneumonia OR nosocomial 
infection OR septic shock). The bibliographies of relevant articles were also hand searched. We performed an updated PubMed search on October 1, 2010.

\section{Study selection criteria}

We selected for inclusion in our review, case-control or cohort studies (either prospective or retrospective) or clinical trials that provided data on the association between thyroid hormones at baseline and the outcome of patients of any age with sepsis or septic shock. We considered baseline thyroid function tests as those referring to the time of diagnosis of sepsis or the time of admission in the ICU. We specifically evaluated English, French, German, Italian, and Spanish language articles.

\section{Data extraction}

Data extracted from each of the included studies were those referring to the study design, the characteristics of the study population and the subgroups of patients compared, the baseline values of thyroid hormones, and their statistical association with the patient outcome through univariate or multivariate analysis, where reported. We also extracted data on the correlation of the thyroid hormones at baseline with sepsis prognostic scores.

\section{Results}

\section{Characteristics of the included studies}

From the literature searches that we performed in PubMed, we retrieved a total of 3633 articles. After first screening, based on the title and the abstract, we selected 202 articles for further detailed evaluation, after which, we identified nine studies as eligible for inclusion in this review (12-19). The process of selecting articles for inclusion in this review is depicted graphically in Fig. 1.

All of the nine included studies had a prospective cohort design. Five of the studies involved children $(1,13-15,17)$, two additional studies involved exclusively neonates $(12,16)$, and the remaining two studies involved adults $(18,19)$. Mortality was the outcome evaluated in eight of the studies $(1,12-19)$, while in the remaining study, the outcome evaluated was the length of stay in the pediatric ICU (PICU) (13). In six of the included studies, it was specifically reported that the blood samples for thyroid hormone measurements were taken before administration of dopamine $(1,12-16,19)$.

\section{Association of thyroid hormones at baseline with outcome}

In Table 1, we present data on the association between serum thyroid hormone levels at baseline and the outcome of patients with sepsis or septic shock.

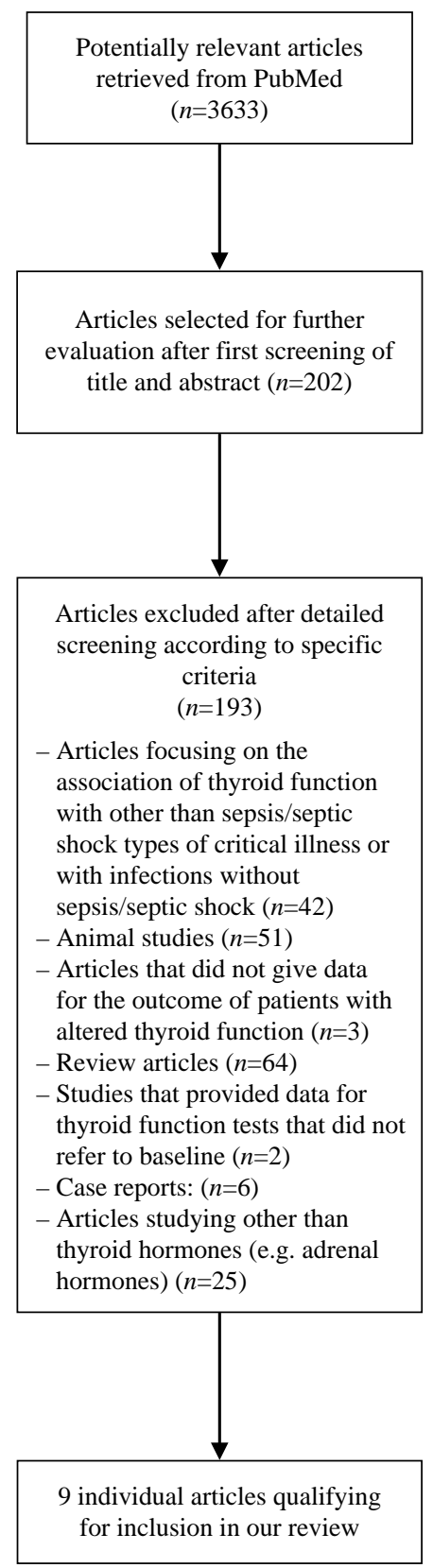

Figure 1 Flow diagram of the detailed process of the selection of articles for inclusion in our review.

Specifically, six of the nine studies included in this review showed, by univariate analysis, that among patients with sepsis or septic shock those with an unfavorable outcome had lower baseline serum levels of, either total or free, $\mathrm{T}_{3}$ or $\mathrm{T}_{4}$, than those with a favorable outcome $(12-16,19)$. In two other studies that involved children and adults, who in both studies were admitted in the ICU due to septic shock, there was no difference in baseline $\mathrm{T}_{3}$ or $\mathrm{T}_{4}$ between non-survivors and survivors 


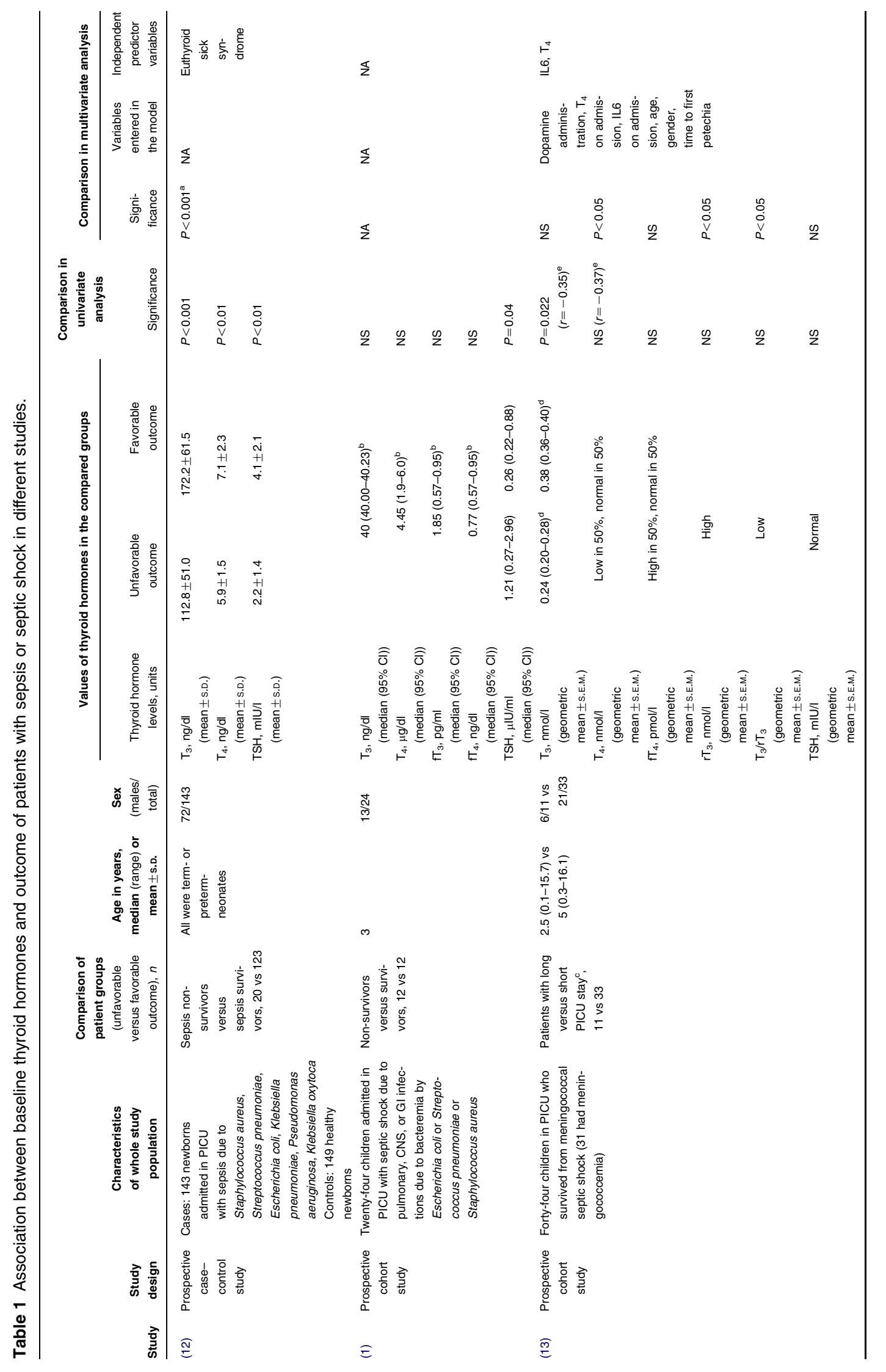

www.eje-online.org 


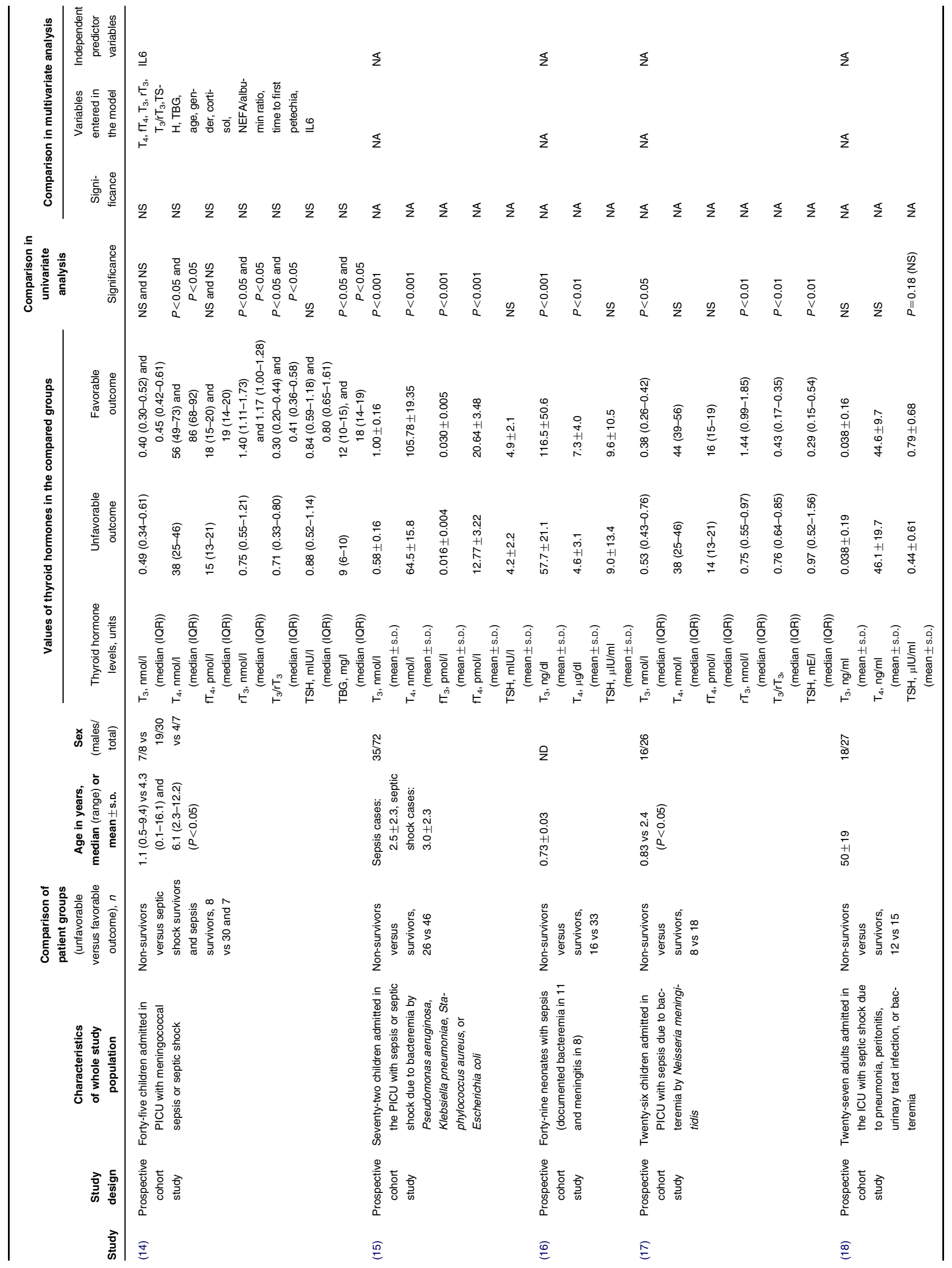




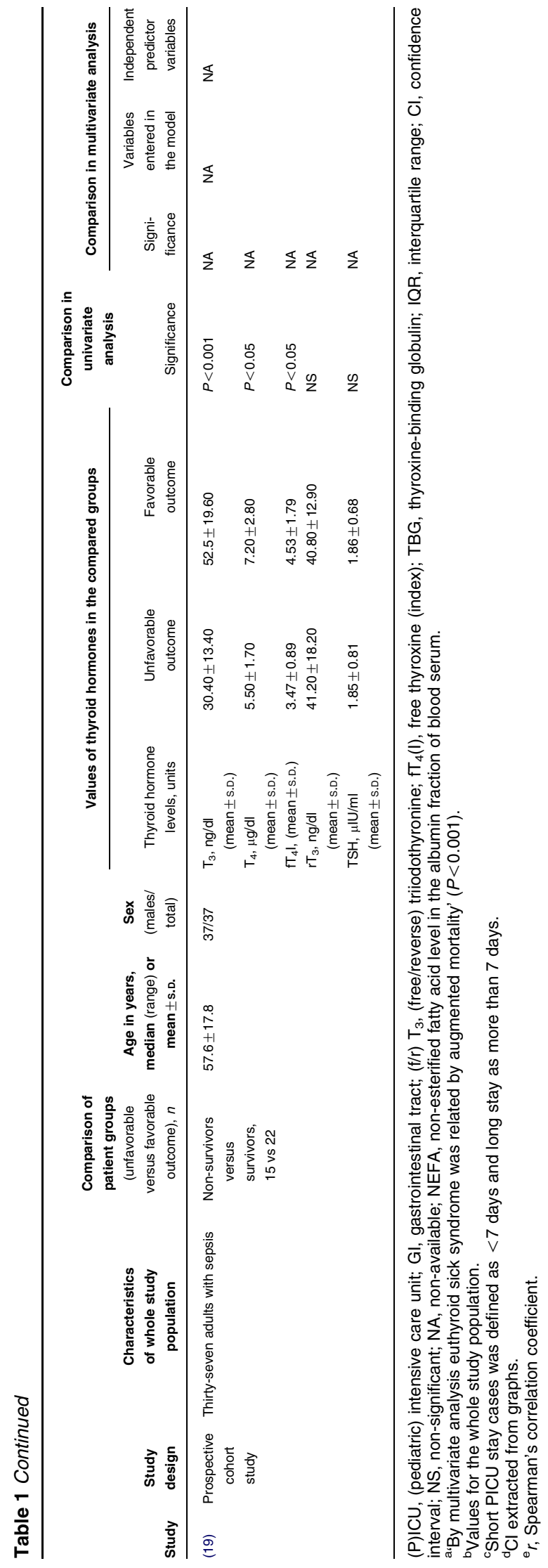

$(1,18)$. In the remaining study, which evaluated children with meningococcal sepsis admitted to the PICU, those who did not survive had higher baseline serum levels of $T_{3}$ than those who survived, while no difference was detected in the total and free $\mathrm{T}_{4}$ levels (17). In this study, non-survivors also had higher baseline levels of TSH.

Higher baseline TSH values in non-survivors were also observed in another study that evaluated children with septic shock admitted to the PICU. This study did not demonstrate differences in the levels of $\mathrm{T}_{3}$ or $\mathrm{T}_{4}$ between non-survivors and survivors (1). On the contrary, lower baseline TSH was associated with higher mortality in a study that evaluated septic neonates admitted in the ICU (12); this was also accompanied with lower $\mathrm{T}_{3}$ and $\mathrm{T}_{4}$. The baseline TSH levels in the remaining six studies did not differ between patients with an unfavorable outcome compared with those with a favorable outcome. In addition, a lower $\mathrm{rT}_{3}$ value and a higher $\mathrm{T}_{3} / \mathrm{rT}_{3}$ ratio were associated with an adverse outcome in two studies $(14,17)$, whereas non-significant findings were observed in the other two studies that assessed the same parameters $(13,19)$.

Three of the included studies further evaluated the above-described associations in multivariate analysis. One of these studies showed that in pediatric patients who survived meningococcal septic shock, lower baseline serum $\mathrm{T}_{4}$ was an independent predictor of an unfavorable outcome, specifically prolonged ICU stay (13). The baseline interleukin 6 (IL6) level was also independently associated with this outcome. The length of ICU stay was estimated to increase by 15\% for every doubling of the IL6 concentration and 16\% for every $10 \mathrm{nmol} / \mathrm{l}$ decrease in the $\mathrm{T}_{4}$ level (13). The second study that included pediatric ICU patients with meningococcal sepsis or septic shock showed that the effect of the thyroid function tests on mortality lost significance in the multivariate analysis, and that IL6 was the only independent predictor of this outcome (14). In the remaining study, which was performed on newborns admitted to the ICU with bacterial sepsis, the presence of euthyroid sick syndrome was independently associated with mortality (12).

In Table 2, we present data on the correlation of thyroid function tests at baseline with various sepsis prognostic scores. Such associations were reported in three of the nine included studies, which all evaluated children with meningococcal sepsis or septic shock admitted to the PICU $(13,14,17)$. In one of these studies, both the pediatric risk of mortality (PRISM) score and the sequential organ failure assessment score had a moderate negative correlation with the baseline $\mathrm{T}_{4}$ value (14). In another study, the PRISM score had a rather weak positive correlation with baseline TSH (17). In the remaining study, no significant relevant associations were observed (13). 
Table 2 Correlation between baseline thyroid hormones and sepsis prognostic scores in patients with sepsis or septic shock included in different studies.

\begin{tabular}{|c|c|c|c|c|c|c|c|}
\hline \multirow[b]{2}{*}{ Study } & \multirow{2}{*}{$\begin{array}{l}\text { Baseline sepsis prognostic } \\
\text { score, median (range) or } \\
\text { mean } \pm \text { s.D. (patients with } \\
\text { unfavorable versus } \\
\text { favorable outcome) }\end{array}$} & \multicolumn{6}{|c|}{ Correlation of thyroid hormones with sepsis prognostic score } \\
\hline & & $T_{3}$ & $\mathrm{~T}_{4}$ & $\mathrm{fT}_{3}$ & $\mathrm{fT}_{4}$ & TSH & TBG \\
\hline (13) & $\begin{array}{l}\text { PRISM: } 24 \text { (12-46) vs } \\
20(9-35)\end{array}$ & NS & NS & NS & NS & NS & NS \\
\hline$(14)$ & $\begin{array}{l}\text { PRISM: } 32(23-43) \text { vs } \\
(21(8-35) \text { and } 9(5-13)) \\
\text { SOFA: } 15(13-19) \text { vs } \\
(9(3-17) \text { and } 2(0-6))\end{array}$ & NS & $\begin{array}{l}r=-0.62 \\
\quad(P<0.05) \\
r=-0.69 \\
\quad(P<0.05)\end{array}$ & NS & NS & NS & $\begin{array}{r}r=-0.54 \\
\quad(P<0.05) \\
r=-0.57 \\
\quad(P<0.05)\end{array}$ \\
\hline$(17)$ & $\begin{array}{l}\text { PRISM: } 31(29-34) \text { vs } \\
\quad 17(14-17)\end{array}$ & $\begin{array}{c}r=0.29 \\
(\mathrm{NS})\end{array}$ & $\begin{array}{l}r=-0.34 \\
(\mathrm{NS})\end{array}$ & ND & $\begin{array}{c}r=-0.41 \\
(\mathrm{NS})\end{array}$ & $\begin{aligned} r= & 0.42 \\
& (P<0.05)\end{aligned}$ & ND \\
\hline
\end{tabular}

$\mathrm{fT}_{3}$, free triiodothyronine; $\mathrm{fT}_{4}$, free thyroxine; TBG, thyroxine-binding globulin; PRISM, pediatric risk of mortality score; SOFA, sequential organ failure assessment score; APACHE, acute physiologic and chronic health evaluation score; NS, non-significant; ND, no data were reported; $r$, Spearman's correlation-coefficient.

\section{Discussion}

The majority (six out of nine) of the evaluated relevant studies showed that lower baseline thyroid hormone values, either $\mathrm{T}_{3}$ or $\mathrm{T}_{4}$, are associated with worse outcome for patients with sepsis or septic shock. The above observations apply mainly to children rather than to adults, as the latter group was evaluated in only two of the included studies. Still, definite conclusions on the above issue cannot be drawn on the basis of the data available herein, as the associations observed were not always consistent between the included studies, or within each study with regard to different thyroid function tests evaluated. Moreover, the association of thyroid hormones at baseline and the outcome of patients with sepsis or septic shock was not commonly evaluated in appropriate multivariate models to adjust for the effect of potential confounders.

It is interesting that one of the included studies showed that, among the 26 children with meningococcal sepsis studied, the 18 who survived had lower $\mathrm{T}_{3}$ levels at PICU admission than the 8 who did not survive (17). This finding stands in contrast to the rest of the included studies, which either showed the opposite or no relevant association. One potential explanation for the discordant findings of the study in this regard is that ten of the survivors received treatment with dopamine, whereas the non-survivors received norepinephrine or dobutamine. Dopamine can suppress the pituitary release of TSH and thus potentially the production of $\mathrm{T}_{3}$ (20), while norepinephrine is believed to stimulate the secretion of TSH (21). Notably, the non-survivors in this study also had higher TSH levels (17). Yet, it was not specifically stated whether dopamine administration preceded the collection of blood samples for the thyroid hormone measurements. However, in the great majority of the remaining studies, thyroid hormone measurements were performed prior to dopamine use $(1,12-15,19)$.
In addition, in the study, in which higher $\mathrm{T}_{3}$ levels were observed in non-survivors of meningococcal septic shock, the age of the non-survivors was significantly lower than that of the survivors (10 vs 29 months respectively) (17). The changes that occur in thyroid hormone levels during the first month of life could, at least in part, account for the differences in the $\mathrm{T}_{3}$ levels observed in this study. Specifically in neonates, the plasma thyroid hormone levels are typically elevated compared with those in older children (22). This is related to the TSH surge that occurs in the immediate postnatal period and to the elevated TBG levels secondary to maternal estrogen (22). In normal term neonates, the total and free $\mathrm{T}_{4}$ levels fall gradually over the next 4-6 weeks but remain higher than in older children and adults for a few months. The $\mathrm{T}_{3}$ levels gradually reach those of infancy, between 2 and 12 weeks of life $(22,23)$. In early neonatal life, there has also been observed an increased activity of type III deiodinase (D3) enzyme with secondary increase in $\mathrm{rT}_{3}$ levels and increase in the degradation of $\mathrm{T}_{3}$ to $\mathrm{T}_{2}$, which reaches the adult range during the fourth postnatal month $(22,23)$.

It is questionable whether the findings of our review can be applicable to adult patients with sepsis or septic shock, who were evaluated in only two of the included studies. Relevant data suggest that children have different hemodynamic responses to critical illness and septic shock. Children more commonly suffer from progressive cardiac failure than adults and can respond to inotropic therapy (24). Mortality in pediatric septic shock is usually lower than in adults (24).

It is generally accepted that the alterations in thyroid hormones observed during critical illness constitute part of an adaptive metabolic response. This is based on the finding that the great majority of patients recover normal thyroid function after the critical illness subsides (25). It has also been suggested that the decrease in metabolic function observed during the systemic inflammatory response syndrome and the accompanying multiorgan 
dysfunction may help protect cell survival (26). Still, thyroid disorders are relatively common in the general population, with an estimated prevalence of $1-10 \%$ (27). The presence of even subclinical abnormalities might be important (28), as subclinical hypothyroidism has been linked to excess mortality in certain patient groups (28, 29). Some studies have also found that a subset of patients with critical illness can have true hypothyroidism (11). High TSH or reduced $\mathrm{rT}_{3}$ can be suggestive of such a diagnosis $(11,30)$. Thus, the findings of some of the studies included in our review that higher TSH, lower $\mathrm{rT}_{3}$, or lower $\mathrm{T}_{3}$ and $\mathrm{T}_{4}$ are associated with an unfavorable outcome of patients with sepsis or septic shock could imply that, at least for a minority of these patients, thyroid hypofunction during sepsis or septic shock might influence per se the outcome of this condition. This hypothesis merits further evaluation in appropriately designed studies.

Some studies performed in animal models of sepsis or septic shock support the hypothesis that relative thyroid insufficiency is associated with a worse outcome. For example, lower baseline serum $\mathrm{T}_{4}$ and free $\mathrm{T}_{4}$ have been associated with decreased likelihood for survival in severely ill dogs (puppies) with parvoviral diarrhea (31). In an experimental sepsis model in rats, those that were previously thyroidectomized showed abolishment of the hyperdynamic response that physiologically accompanies early-stage sepsis. In the thyroidectomized animals (32), it was observed that the administration of $\mathrm{T}_{4}$ reversed the decrease in survival.

Another experimental study in rats showed that thyroid hormone supplementation during sepsis can increase survival (33). A particular beneficial effect of thyroid hormone administration in rats with experimentally induced sepsis has been documented on lung mechanics and histology, which was mainly attributed to enhanced synthesis of surfactant $(34,35)$. Still, other studies on experimentally induced sepsis have failed to show a benefit of thyroid hormone replacement $(7,32$, 36). In humans, there is little evidence regarding thyroid hormone substitution during critical illness. Of note, some relevant clinical studies have suggested that $\mathrm{T}_{4}$ supplementation can lead to reduction in the needs for vasoactive drug administration in circulatory shock (37).

Thyroid hormone supplementation during sepsis or septic shock can lead to a reciprocal decrease in TSH. This issue needs particular attention, as there appears to be a rather complex pathophysiological interplay between TSH and the immune system. Specifically, TSH has been shown to affect the function of various types of hematopoietic and immune system cells that express the TSH receptor $(38,39)$. Such cells mainly include subsets of hematopoietic cells in the bone marrow, as well as peripheral monocytes, dendritic cells, and T-lymphocytes. Furthermore, some of the above cell types can produce biologically active TSH that can have autocrine and paracrine actions, which can influence the early stages of the immune response to an antigen $(38,39)$. These actions can include the regulation of the synthesis and release of mediators of inflammation, such as IL6 and tumor necrosis factor- $\alpha$ $(\mathrm{TNF}-\alpha)$. Various immune system cells have also been found to express $\mathrm{T}_{3}$, a process that is under the influence of TSH (40). It has thus been hypothesized that the immune system cells can affect the systemic thyroid hormone activity.

It is debatable whether the data included in our review regarding the association between thyroid function and sepsis or septic shock can be extrapolated to other types of critical illness. Several inflammatory cytokines, such as IL1 $\beta$, IL6, and TNF- $\alpha$, can suppress, via direct or indirect pathways, the thyroid function at different levels $(41,42)$. In sepsis, the increase in the production of pro-inflammatory cytokines is more pronounced than that in other types of critical illness (43, 44). In this respect, baseline levels of thyroid hormones, including $\mathrm{T}_{4}, \mathrm{~T}_{3}$, and $\mathrm{TSH}$, can be substantially lower in septic patients than in non-septic patients with critical illness of similar severity (45). The degree of endothelial activation and dysfunction can also be greater in sepsis than in other types of critical illness, as reflected by higher levels of E-selectin, intercellular adhesion molecule-1, and von Willebrand factor activity that have been observed in some studies $(43,44,46)$.

The findings of our review regarding the association between thyroid hormone abnormalities and the outcome of patients with sepsis or septic shock indicate that these abnormalities could be of prognostic value. In the studies included in our review, the association between established sepsis prognostic systems and baseline thyroid hormones was at the most moderate. Thus, the prognostic value of thyroid hormones may be independent of other prognostic markers. Likewise, other studies performed in critically ill patients have shown that taking into consideration the baseline thyroid function tests can add to the predictive capacity of the APACHE score $(11,47)$.

In conclusion, the majority of the identified studies that evaluated the baseline thyroid function tests in patients with sepsis or septic shock provide data that favor the existence of an association between lower $\mathrm{T}_{3}$ or $\mathrm{T}_{4}$ and worse outcome. Since thyroid hormone abnormalities are very common in septic patients, future studies should aim to more clearly establish the strength of the above-mentioned association or even examine whether a causal relationship between thyroid hypofunction and adverse outcome exists. The role of the thyroid hormone abnormalities as predictors of outcome of septic patients on top of the known risk prognostic scoring systems warrants also further evaluation.

\section{Declaration of interest}

The authors declare that there is no conflict of interest that could be perceived as prejudicing the impartiality of the review reported. 


\section{Funding}

This review did not receive any specific grant from any funding agency in the public, commercial or not-for-profit sector.

\section{References}

1 Lodha R, Vivekanandhan S, Sarthi M, Arun S \& Kabra SK. Thyroid function in children with sepsis and septic shock. Acta Paediatrica 200796 406-409. (doi:10.1111/j.1651-2227.2007.00135.x)

2 Iglesias P, Muñoz A, Prado F, Guerrero MT, Macías MC, Ridruejo E, Tajada P \& Díez JJ. Alterations in thyroid function tests in aged hospitalized patients: prevalence, etiology and clinical outcome. Clinical Endocrinology 2009 70 961-967. (doi:10.1111/j.13652265.2008.03421.x

3 Simons RJ, Simon JM, Demers LM \& Santen RJ. Thyroid dysfunction in elderly hospitalized patients. Effect of age and severity of illness. Archives of Internal Medicine $1990 \mathbf{1 5 0}$ 1249-1253. (doi:10.1001/archinte.150.6.1249)

4 Warner MH \& Beckett GJ. Mechanisms behind the non-thyroidal illness syndrome: an update. Journal of Endocrinology 2010205 1-13. (doi:10.1677/JOE-09-0412)

5 Sakharova OV \& Inzucchi SE. Endocrine assessments during critical illness. Critical Care Clinics 200723 467-490. (doi:10. 1016/j.ccc.2007.05.007)

6 Peeters RP, Wouters PJ, Kaptein E, van Toor H, Visser TJ \& Van den Berghe G. Reduced activation and increased inactivation of thyroid hormone in tissues of critically ill patients. Journal of Clinical Endocrinology and Metabolism 2003 88 3202-3211. (doi:10. 1210/jc.2002-022013)

7 Chopra IJ. Clinical review 86: euthyroid sick syndrome: is it a misnomer? Journal of Clinical Endocrinology and Metabolism 1997 82 329-334. (doi:10.1210/jc.82.2.329)

8 Slag MF, Morley JE, Elson MK, Crowson TW, Nuttall FQ \& Shafer RB. Hypothyroxinemia in critically ill patients as a predictor of high mortality. Journal of the American Medical Association 1981 24 543-545.

9 Peeters RP, Wouters PJ, van Toor H, Kaptein E, Visser TJ \& Van den Berghe G. Serum 3,3',5'-triiodothyronine $\left(\mathrm{rT}_{3}\right)$ and 3,5,3'triiodothyronine $/ \mathrm{rT}_{3}$ are prognostic markers in critically ill patients and are associated with postmortem tissue deiodinase activities. Journal of Clinical Endocrinology and Metabolism 200590 4559-4565. (doi:10.1210/jc.2005-0535)

10 Plikat K, Langgartner J, Buettner R, Bollheimer LC, Woenckhaus U, Schölmerich J \& Wrede CE. Frequency and outcome of patients with nonthyroidal illness syndrome in a medical intensive care unit. Metabolism 200756 239-244. (doi:10.1016/j.metabol.2006.09.020)

11 Rothwell PM, Udwadia ZF \& Lawler PG. Thyrotropin concentration predicts outcome in critical illness. Anaesthesia $1993 \mathbf{4 8}$ 373-376. (doi:10.1111/j.1365-2044.1993.tb07006.x)

12 Kurt A, Aygun AD, Sengul I, Sen Y, Kurt AN \& Ustundag B. Serum thyroid hormones levels are significantly decreased in septic neonates with poor outcome. Journal of Endocrinological Investigation, 2010. (doi:10.3275/7261)

13 den Brinker M, Dumas B, Visser TJ, Hop WC, Hazelzet JA, Festen DA, Hokken-Koelega AC \& Joosten KF. Thyroid function and outcome in children who survived meningococcal septic shock. Intensive Care Medicine 200531 970-976. (doi:10.1007/s00134005-2671-8)

14 den Brinker M, Joosten KF, Visser TJ, Hop WC, de Rijke YB, Hazelzet JA, Boonstra VH \& Hokken-Koelega AC. Euthyroid sick syndrome in meningococcal sepsis: the impact of peripheral thyroid hormone metabolism and binding proteins. Journal of Clinical Endocrinology and Metabolism 200590 5613-5720. (doi:10.1210/jc.2005-0888)

15 Yildizdaş D, Onenli-Mungan N, Yapicioğlu H, Topaloğlu AK, Sertdemir Y \& Yüksel B. Thyroid hormone levels and their relationship to survival in children with bacterial sepsis and septic shock. Journal of Pediatric Endocrinology and Metabolism 200417 1435-1442.

16 Das BK, Agarwal P, Agarwal JK \& Mishra OP. Serum cortisol and thyroid hormone levels in neonates with sepsis. Indian Journal of Pediatrics 200269 663-665. (doi:10.1007/BF02722699)

17 Joosten KF, de Kleijn ED, Westerterp M, de Hoog M, Eijck FC, Hop WCJ, Voort EV, Hazelzet JA \& Hokken-Koelega AC. Endocrine and metabolic responses in children with meningoccocal sepsis: striking differences between survivors and nonsurvivors. Journal of Clinical Endocrinology and Metabolism $2000 \mathbf{8 5} 3746-3753$. (doi:10.1210/jc.85.10.3746)

18 Leon-Sanz M, Lorente JA, Larrodera L, Ros P, Alvarez J, Esteban AE \& Landin L. Pituitary-thyroid function in patients with septic shock and its relation with outcome. European Journal of Medical Research 19972 477-482.

19 Mangas-Rojas A, García-Rojas JF, Barba Chacón A, Millán NúñezCortés J \& Zamora-Madaria E. Changes in the hypophysealthyroid axis and their prognostic value in sepsis. Revista Clínica Española 1990187 395-398.

20 Van den Berghe G, de Zegher F \& Lauwers P. Dopamine suppresses pituitary function in infants and children. Critical Care Medicine 199422 1747-1753. (doi:10.1007/BF00866735)

21 Fukuda S. Correlations between function of pituitary-thyroid axis and metabolism of catecholamines by the fetus at delivery. Clinical Endocrinology 198727 331-338. (doi:10.1111/j.1365-2265. 1987.tb01159.x)

22 Cavallo L, Margiotta W, Kernkamp C \& Pugliese G. Serum levels of thyrotropin, thyroxine, 3,3',5-triiodothyronine and 3,3',5'-triiodothyronine (reverse $\mathrm{T}_{3}$ ) in the first six days of life. Acta Paediatrica Scandinavica 198069 43-47. (doi:10.1111/j.1651-2227.1980. tb07027.x)

23 Santini F, Chiovato L, Ghirri P, Lapi P, Mammoli C, Montanelli L, Scartabelli G, Ceccarini G, Coccoli L, Chopra IJ, Boldrini A \& Pinchera A. Serum iodothyronines in the human fetus and the newborn: evidence for an important role of placenta in fetal thyroid hormone homeostasis. Journal of Clinical Endocrinology and Metabolism 199984 493-498. (doi:10.1210/jc.84.2.493)

24 Ceneviva G, Paschall JA, Maffei F \& Carcillo JA. Hemodynamic support in fluid-refractory pediatric septic shock. Pediatrics 1998 102 19. (doi:10.1542/peds.102.2.e19)

25 Attia J, Margetts P \& Guyatt G. Diagnosis of thyroid disease in hospitalized patients: a systematic review. Archives of Internal Medicine 1999159 658-665. (doi:10.1001/archinte.159.7.658)

26 Singer M, De Santis V, Vitale D \& Jeffcoate W. Multiorgan failure is an adaptive, endocrine-mediated, metabolic response to overwhelming systemic inflammation. Lancet $2004 \mathbf{3 6 4} 545-548$. (doi:10.1016/S0140-6736(04)16815-3)

27 Stone MB \& Wallace RB (eds). Committee on Medicare Coverage of Routine Thyroid Screening. Washington DC: National Academies Press, 2003.

28 Haentjens P, Van Meerhaeghe A, Poppe K \& Velkeniers B. Subclinical thyroid dysfunction and mortality: an estimate of relative and absolute excess all-cause mortality based on time-to-event data from cohort studies. European Journal of Endocrinology 2008159 329-341. (doi:10.1530/EJE-08-0110)

29 Razvi S, Shakoor A, Vanderpump M, Weaver JU \& Pearce SH. The influence of age on the relationship between subclinical hypothyroidism and ischemic heart disease: a meta-analysis. Journal of Clinical Endocrinology and Metabolism $2008 \mathbf{9 3}$ 2998-3007. (doi:10.1210/jc.2008-0167)

30 Burmeister LA. Reverse $\mathrm{T}_{3}$ does not reliably differentiate hypothyroid sick syndrome from euthyroid sick syndrome. Thyroid 19955 435-441. (doi:10.1089/thy.1995.5.435)

31 Schoeman JP \& Herrtage ME. Serum thyrotropin, thyroxine and free thyroxine concentrations as predictors of mortality in critically ill puppies with parvovirus infection: a model for human paediatric critical illness? Microbes and Infection $2008 \mathbf{1 0}$ 203-207. (doi:10.1016/j.micinf.2007.11.002) 
32 Moley JF, Ohkawa M, Chaudry IH, Clemens MG \& Baue AE. Hypothyroidism abolishes the hyperdynamic phase and increases susceptibility to sepsis. Journal of Surgical Research $1984 \mathbf{3 6}$ 265-273. (doi:10.1016/0022-4804(84)90097-0)

33 Inan M, Koyuncu A, Aydin C, Turan M, Gokgoz S \& Sen M. Thyroid hormone supplementation in sepsis: an experimental study. Surgery Today 200333 24-29. (doi:10.1007/s005950 300004)

34 Dulchavsky SA \& Bailey J. Triiodothyronine treatment maintains surfactant synthesis during sepsis. Surgery 1992112 475-479.

35 Dulchavsky SA, Kennedy PR, Geller ER, Maitra SR, Foster WM \& Langenbeck EG. $\mathrm{T}_{3}$ preserves respiratory function in sepsis. Journal of Trauma 199131 753-758. (doi:10.1097/00005373199106000-00004)

36 Little JS. Effect of thyroid hormone supplementation on survival after bacterial infection. Endocrinology 1985117 1431-1435. (doi:10.1210/endo-117-4-1431)

37 Zuppa AF, Nadkarni V, Davis L, Adamson PC, Helfaer MA, Elliott MR, Abrams J \& Durbin D. The effect of a thyroid hormone infusion on vasopressor support in critically ill children with cessation of neurologic function. Critical Care Medicine 200432 2318-2322. (doi:10.1097/01.CCM.0000146133.52982.17)

38 Wang HC \& Klein JR. Immune function of thyroid stimulating hormone and receptor. Critical Reviews in Immunology 200121 323-337.

39 Klein JR. Physiological relevance of thyroid stimulating hormone and thyroid stimulating hormone receptor in tissues other than the thyroid. Autoimmunity 200336 417-421. (doi:10.1080/ 08916930310001603019)

40 Csaba G \& Pállinger E. Thyrotropic hormone (TSH) regulation of triiodothyronine $(\mathrm{T}(3))$ concentration in immune cells. Inflammation Research 200958 151-154. (doi:10.1007/ s00011-008-8076-8)
41 van der Poll T, Romijn JA, Wiersinga WM \& Sauerwein HP. Tumor necrosis factor: a putative mediator of the sick euthyroid syndrome in man. Journal of Clinical Endocrinology and Metabolism 199071 1567-1572. (doi:10.1210/jcem-71-6-1567)

42 McIver B \& Gorman CA. Euthyroid sick syndrome: an overview. Thyroid 19977 125-132. (doi:10.1089/thy.1997.7.125)

43 Casey LC, Balk RA \& Bone RC. Plasma cytokine and endotoxin levels correlate with survival in patients with sepsis syndrome. Annals of Internal Medicine 1993119 771-777.

44 Cowley HC, Heney D, Gearing AJ, Hemingway I \& Webster NR. Increased circulating adhesion molecule concentrations in patients with the systemic inflammatory response syndrome: a prospective cohort study. Critical Care Medicine 199422 651-657. (doi:10.1097/00003246-199404000-00022)

45 Mönig H, Arendt T, Meyer M, Kloehn S \& Bewig B. Activation of the hypothalamo-pituitary-adrenal axis in response to septic or non-septic diseases - implications for the euthyroid sick syndrome. Intensive Care Medicine 199925 1402-1406. (doi:10.1007/ s001340051088)

46 Cummings CJ, Sessler CN, Beall LD, Fisher BJ, Best AM \& Fowler AA III. Soluble E-selectin levels in sepsis and critical illness. Correlation with infection and hemodynamic dysfunction. American Journal of Respiratory and Critical Care Medicine 1997156 431-437.

47 Chinga-Alayo E, Villena J, Evans AT \& Zimic M. Thyroid hormone levels improve the prediction of mortality among patients admitted to the intensive care unit. Intensive Care Medicine 2005 31 1356-1361. (doi:10.1007/s00134-005-2719-9)

Received 2 November 2010

Accepted 15 November 2010 